\title{
Hereditary angioneurotic edema and familial Crohn's disease
}

\author{
Hugh J Freeman MD
}

HJ Freeman. Hereditary angioneurotic edema and familial Crohn's disease. Can J Gastroenterol 2000;14(4):337-339. A 29-year-old man with Crohn's disease involving the ileum and cecum was seen. He had angioneurotic edema with $\mathrm{C1}^{\prime}$ esterase inhibitor deficiency. Later, his 50-year-old mother was evaluated because of abdominal pain. She had recurrent urticaria, $\mathrm{C1}^{\prime}$ esterase inhibitor deficiency and radiographic studies showed Crohn's disease of the ileum. A maternal family history revealed other members affected with either Crohn's disease or angioneurotic edema. The clinical observations in this family suggest that angioneurotic edema associated with $\mathrm{Cl}^{\prime}$ esterase inhibitor deficiency may be closely linked genetically with a familial form of Crohn's disease.

Key Words: C1'esterase deficiency; Complement; Crohn's disease; Familial Crohn's disease; Hereditary angioedema; Serum

\section{Oedème angioneurotique héréditaire et forme familiale de la maladie de Crohn}

RÉSUMÉ : Voici le cas d'un homme de 29 ans souffrant de la maladie de Crohn, avec atteinte de l'iléon et du caecum. Il présentait de l'œedème angioneurotique et avait un déficit en inhibiteur de l'estérase C1. Plus tard, sa mère, âgée de 50 ans, a été examinée pour douleurs abdominales. Elle faisait de l'urticaire récurrente et présentait, elle aussi, un déficit en inhibiteur de l'estérase $\mathrm{Cl}$. Les radiographies ont révélé la présence de la maladie de Crohn avec atteinte de l'iléon. La revue des antécédents familiaux du côté maternel faisait état d'autres cas de la maladie de Crohn ou d'œedème angioneurotique. Les observations cliniques faites sur la famille semblent indiquer que l'œdème angioneurotique associé à un déficit en inhibiteur de l'estérase $\mathrm{C} 1$ peut être génétiquement lié de près à la forme familiale de la maladie de Crohn.
$\mathrm{A}^{\mathrm{in}}$ ltered levels of some complement components occur in patients with inflammatory bowel disease (1). Moreover, inherited deficiencies of complement have been recognized with increasing frequency (2). Of these, homozygous deficiency of the second component of complement (C2) has been reported most often, with an estimated incidence rate of one in 10,000. Most patients with this deficiency are in good health, but some may have clinical disorders including systemic lupus erythematosis, membranoproliferative glomerulonephritis and vasculitis (2). In one report (3) of a patient with inflammatory bowel disease, inherited C2 deficiency was linked to human leukocyte antigen haplotype A10, B18. Because these patients may have autoimmune disorders and seem prone to infection, it was suggested that C2 deficiency predisposed patients to inflam- matory bowel disease. In another report of C2 deficiency, multifocal stenosing ulcerations were described in association with vasculitis (4). Interestingly, this patient had a corticosteroid sensitivity and required recurrent surgical treatment for repeated episodes of intestinal obstruction.

Other complement deficiency states have been associated with gastrointestinal disease. Hereditary angioneurotic edema, for example, is an autosomal dominant condition with an estimated prevalence of one in 150,000 (5). Either deficiency or dysfunction of the $\mathrm{C}^{\prime}$ ' esterase inhibitor is responsible (6), while symptoms and signs of gastrointestinal dysfunction may be present, even without cutaneous, oropharygneal or respiratory findings $(7,8)$. Finally, in a recent report from Budapest (9), the simultaneous occurrence of hereditary angioneurotic edema and Crohn's disease was de-

Department of Medicine (Gastroenterology), University of British Columbia, Vancouver, British Columbia

Correspondence and reprints: Dr Hugh Freeman, ACU F-137 Gastroenterology, University of British Columbia Hospital, 2211 Wesbrook Mall, Vancouver, British Columbia V6T 1W5

Received for publication December 21, 1998. Accepted June 8, 1999 
scribed. The present report describes two additional patients, specifically, a parent-child pair, with both Crohn's disease and angioneurotic edema due to $\mathrm{Cl}^{\prime}$ esterase inhibitor deficiency. An extensive maternal family history for both Crohn's disease and angioneurotic edema was also evident.

\section{CASE PRESENTATION}

Case 1: A 29-year-old man was evaluated in May 1985 at the University of British Columbia (UBC) Hospital, Vancouver, British Columbia because of a six-month history of abdominal pain and diarrhea. Results of fecal studies for bacteriology and parasites were negative. Sigmoidoscopy and rectal biopsy results were normal. Barium radiographic studies showed changes of Crohn's disease involving the terminal ileum and cecum. Colonoscopy revealed inflammatory changes with ulceration in the distal ileum and cecum; the rest of the colon was normal. A cecal polyp, resected by snare polypectomy, and ileocecal biopsies showed inflammatory changes alone, while mucosal biopsies from other sites in the more distal colon were normal; no granulomas were detected. He was treated with sulphasalazine. In December 1986, investigations at the Mayo Clinic, Rochester, Minnesota, including barium radiological studies of the upper and lower gastrointestinal tract and a sigmoidoscopy, confirmed ileocecal Crohn's disease. No other treatment was recommended, and he continued to take sulphasalazine. His symptoms resolved, but in 1987 he redeveloped abdominal pain and fever, and physical examination revealed a right lower quadrant mass. Abdominal ultrasound and computed tomography revealed thickened bowel loops but no abscess. Treatment in hospital with intravenous metronidazole and gentamicin led to resolution of his fever and abdominal pain. Two weeks later, however, symptoms recurred and he was hospitalized for a second time. He was treated with intravenous gentamicin and metronidazole as well as parenteral nutrition. A limited resection of the ileum and right colon was done. Although no granulomas were detected in the resected specimen, inflammatory changes and ulceration were present, consistent with Crohn's disease. There was no evidence of vasculitis. Until he moved to New York City in 1992, he remained asymptomatic and was seen only once annually from 1988 to 1992, inclusive. His upper and lower gastrointestinal tract were evaluated endoscopically in 1989 because of abdominal pain. Except for some gastric and duodenal erosions, changes of Crohn's disease were not detected, and biopsies of his stomach, small intestine (including the 'neoterminal' ileum) and rectum were normal. Symptoms resolved with a course of oral ranitidine.

His past medical history also revealed serum $\mathrm{Cl}^{\prime}$ esterase inhibitor deficiency (ie, $8 \mathrm{mg} / \mathrm{dL}$, normal range 16 to $34 \mathrm{mg} / \mathrm{dL}$ ) and angioneurotic edema. In addition, his maternal grandfather died of a respiratory arrest associated with laryngeal edema and upper airway obstruction. Additional family history revealed that his sister and a maternal uncle had angioneurotic edema, and that a maternal aunt and her two children (ie, male and female first cousins) all had Crohn's disease involving the ileum and colon.
Case 2: The patients 50-year-old mother was first evaluated at the UBC Hospital in January 1988 for abdominal pain. Her past history revealed that, at age 25 years, she experienced cutaneous features of angioneurotic edema after a dental extraction; there were no respiratory symptoms. Since then, she had episodic urticaria. Evaluation in Boston, Massachusetts in 1989 had documented C1' esterase inhibitor deficiency ( $10 \mathrm{mg} / \mathrm{dL}$, normal range 16 to $34 \mathrm{mg} / \mathrm{dL}$ ). In addition to the family history reported for her son (see above), her paternal uncle, living in the Boston area, was previously seen for documented hereditary angioedema with $\mathrm{Cl}^{\prime}$ esterase inhibitor deficiency. Results of a colonoscopy in 1988 were normal, including a rectal biopsy, but a barium study of her small intestine showed ileal inflammatory changes of Crohn's disease. Her symptoms resolved spontaneously without medication, but repeat barium studies of her small intestine did not change.

\section{DISCUSSION}

The present report records the development of two unusual conditions in two family members, a mother-son pair, with both Crohn's disease and angioneurotic edema associated with $\mathrm{Cl}^{\prime}$ esterase inhibitor deficiency. Both conditions appear to have developed in the setting of a genetic background of both Crohn's disease and angioedema in other maternal family members. Given the recent report of a similar case history in the Hungarian literature (9), these findings suggest that the phenotypic expression of these two apparently unrelated conditions may be genetically linked.

The clinical and pathological findings reported here and considered as typical for Crohn's disease involving the small intestine are reminiscent of an earlier description of another rare disorder, recently related to an inherited complement deficiency state. Debray and colleagues (10) described an apparently distinctive syndrome with a constellation of features including repeated episodes of intestinal obstruction, ulcerative stenosis of the small intestine relapsing after surgical resection and steroid sensitivity, or so-called 'cryptogenic multifocal ulcerous stenosing enteritis'. Although the features might be considered fairly typical of findings in small bowel Crohn's disease, Perlemuter and colleagues (4) later described a similar patient with multifocal stenosing ulcerations of the small intestine and a polyarteritis-like vasculitis with inherited C2 deficiency. The authors argued that the pathological findings differed from those typically detected in Crohn's disease, usually characterized by transmural or aphthoid ulcerations, giant cell granulomas and fistula formation. In these patients with $\mathrm{C} 1^{\prime}$ esterase inhibitor deficiency, the clinical and/or pathological features of Crohn's disease were present but granulomas were not detected.

Although these patients may conceivably be at increased risk for the development of laryngeal edema associated with oropharyngeal manipulation, including endoscopic evaluation (8), this did not appear to present a difficulty here in the present case, including the requirement for endotracheal intubation for resective surgical treatment. Nevertheless, it would be prudent to be aware of this condition not only for 
evaluating patients with recurrent abdominal pain or abnormal radiographic studies suggestive of bowel wall edema (8), but also because of the close association with Crohn's disease. As such, invasive endoscopic or surgical procedures may be minimized and prophylactic treatment (10) made available, if necessary.

\section{REFERENCES}

1. Kirsner JB, Shorter RG. Inflammatory Bowel Disease, 4th edn. Baltimore: Williams and Wilkins, 1995:310-1.

2. Agnello V. Complement deficiency states. Medicine (Baltimore) 1978;57:1-23.

3. Slade JD, Luskin AT, Gewurz H, Kraft SC, Kirsner JB, Zeitz HJ. Inherited deficiency of second component of complement and HLA haplotype A10, B18 associated with inflammatory bowel disease. Ann Intern Med 1978;88:796-8.
4. Perlemuter G, Chaussade S, Soubrane O, et al. Multifocal stenosing ulcerations of the small intestine revealing vasculitis associated with C2 deficiency. Gastroenterology 1996;110:1628-32.

5. Donaldson VA. Hereditary angioneurotic edema. Dis Month 1979;26:1-37.

6. Hentges F, Humbel R, Dicato M, Hemmer R, Kuntziger H. Acquired C-1' esterase inhibitor deficiency: case report with emphasis on complement and kallikrein activation during two patterns of clinical manifestations. J Allergy Clin Immunol 1986;78:860-6.

7. Warin RP, Higgs ER. Acute and recurrent abdominal pain due to hereditary angioedema. Br Med J 1982;284:1912.

8. Weinstock LB, Kothari T, Sharma RN, Rosenfeld SI. Recurrent abdominal pain as the sole manifestation of hereditary angioedema in multiple family members. Gastroenterology 1987;93:1116-8.

9. Farkas H, Gyeney L, Nemesanszky E, et al. [Similtaneous occurrence of hereditary angioneurotic edema and Crohn disease]. Orv Hetil 1998;139:1165-9.

10. Debray C, Besancon F, Hardoin JP, et al. Entérite sténosante ulcéreuse plurifocale crytogénétique. Arch Fr Mal App Dig. 1964;53:193-206. 


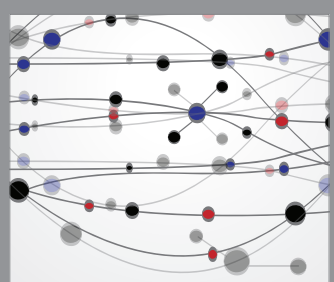

The Scientific World Journal
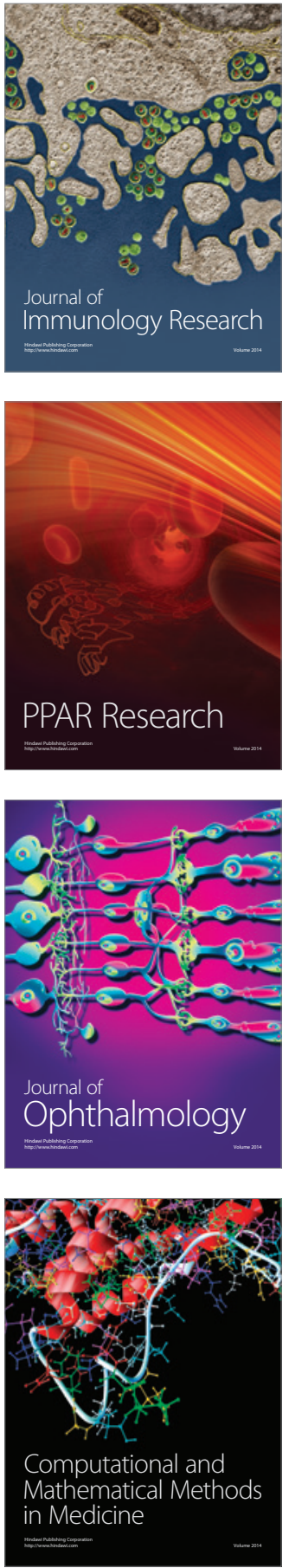

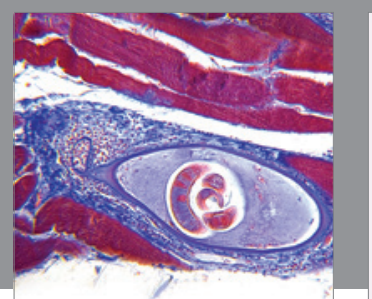

Gastroenterology Research and Practice

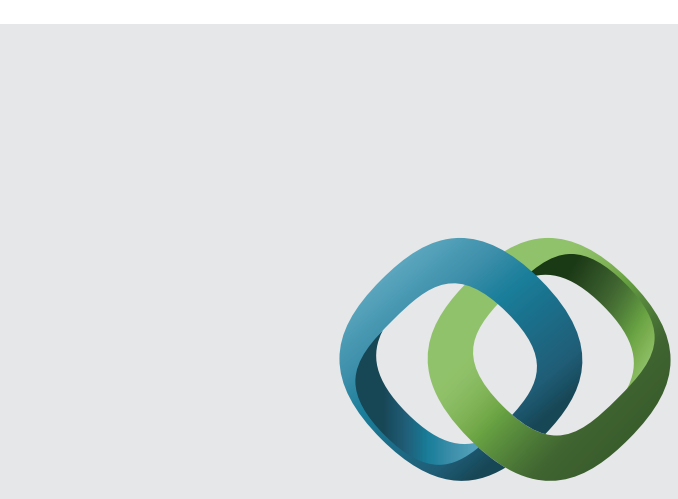

\section{Hindawi}

Submit your manuscripts at

http://www.hindawi.com
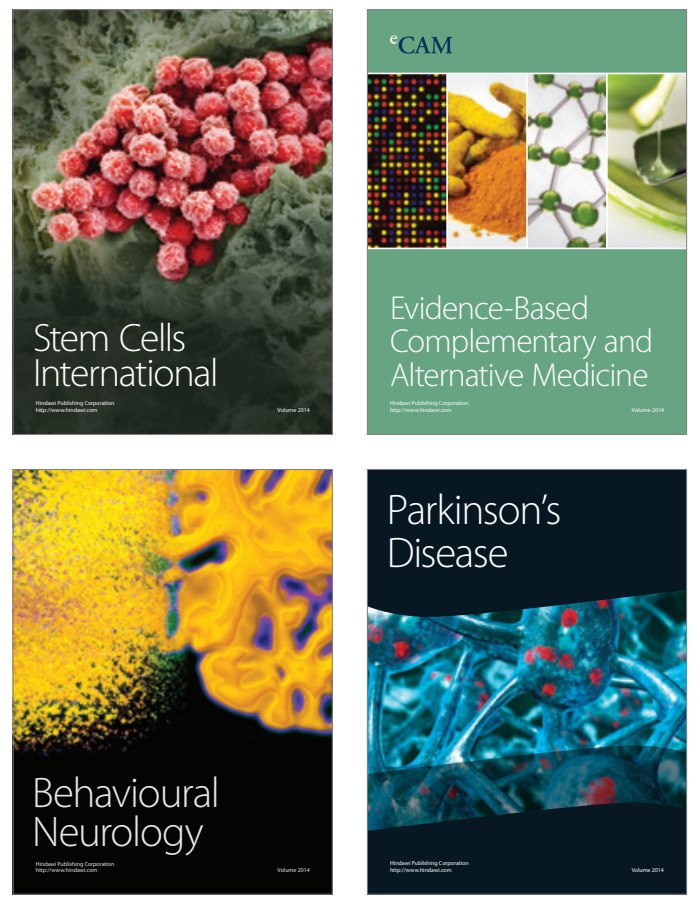
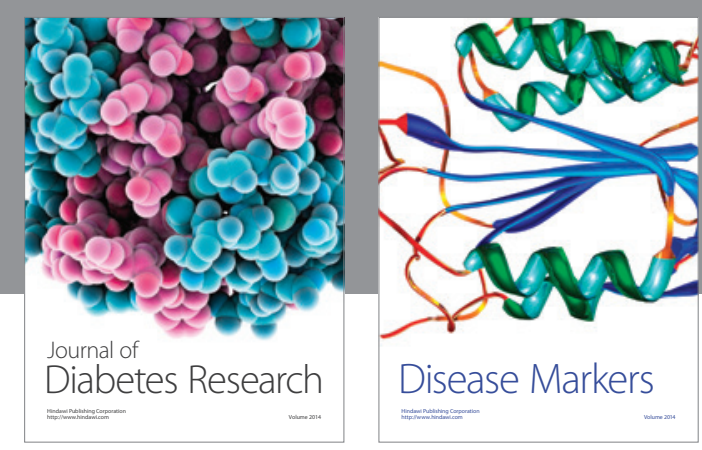

Disease Markers
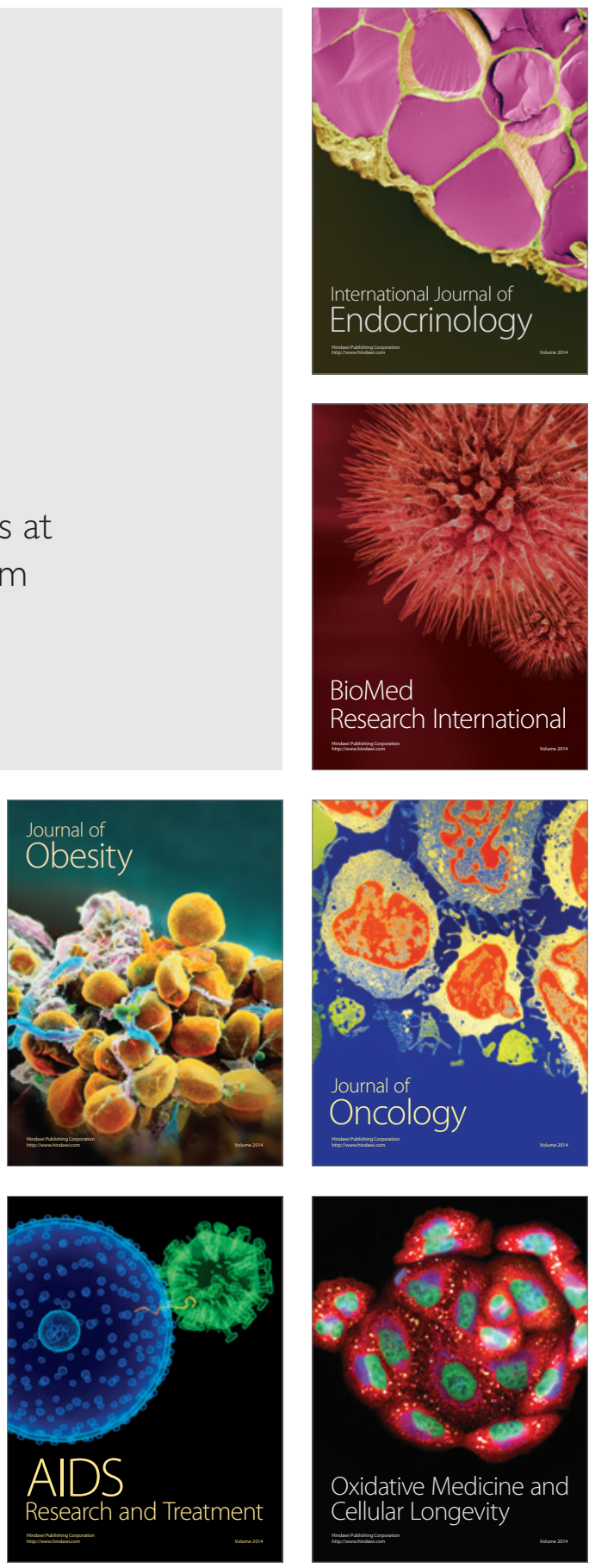